\title{
Carbon dioxide narcosis due to inappropriate oxygen delivery: a case report
}

Thomas Herren ${ }^{1,2^{*}}$ (D), Eva Achermann ${ }^{1,2}$, Thomas Hegi ${ }^{3}$, Adrian Reber ${ }^{4,5}$ and Max Stäubli, ${ }^{6,7}$

\begin{abstract}
Background: Oxygen delivery to patients with chronic obstructive pulmonary disease may be challenging because of their potential hypoxic ventilatory drive. However, some oxygen delivery systems such as non-rebreathing face masks with an oxygen reservoir bag require high oxygen flow for adequate oxygenation and to avoid carbon dioxide rebreathing.

Case presentation: A 72-year-old Caucasian man with severe chronic obstructive pulmonary disease was admitted to the emergency department because of worsening dyspnea and an oxygen saturation of $81 \%$ measured by pulse oximetry. Oxygen was administered using a non-rebreathing mask with an oxygen reservoir bag attached. For fear of removing the hypoxic stimulus to respiration the oxygen flow was inappropriately limited to 4L/ minute. The patient developed carbon dioxide narcosis and had to be intubated and mechanically ventilated.

Conclusions: Non-rebreathing masks with oxygen reservoir bags must be fed with an oxygen flow exceeding the patient's minute ventilation ( $>6-10 \mathrm{~L} /$ minute.). If not, the amount of oxygen delivered will be too small to effectively increase the arterial oxygen saturation. Moreover, the risk of carbon dioxide rebreathing dramatically increases if the flow of oxygen to a non-rebreathing mask is lower than the minute ventilation, especially in patients with chronic obstructive pulmonary disease and low tidal volumes. Non-rebreathing masks (with oxygen reservoir bags) must be used cautiously by experienced medical staff and with an appropriately high oxygen flow of 10-15 L/minute. Nevertheless, arterial blood gases must be analyzed regularly for early detection of a rise in partial pressure of carbon dioxide in arterial blood in patients with chronic obstructive pulmonary disease and a hypoxic ventilatory drive. These patients are more safely managed using a nasal cannula with an oxygen flow of 1-2L/ minute or a simple face mask with an oxygen flow of $5 \mathrm{~L} /$ minute.
\end{abstract}

Keywords: Non-rebreathing mask, Oxygen inhalation therapy, Obstructive lung diseases, Hypercapnia, Respiratory acidosis

\section{Background}

In 2011, chronic obstructive pulmonary disease (COPD) had a global prevalence of $12 \%$ and was the third leading cause of death in the USA [1]. Oxygen $\left(\mathrm{O}_{2}\right)$ delivery to COPD patients with an acute disease exacerbation remains challenging. High inspired $\mathrm{O}_{2}$ concentrations should be used with caution, because COPD patients may breathe with a hypoxic drive [2]. To avoid carbon

\footnotetext{
* Correspondence: thomas.herren@spital-limmattal.ch

${ }^{1}$ University of Zurich, Medical Faculty, Zurich, Switzerland

${ }^{2}$ Department of Medicine, Limmattal Hospital, 100 Urdorferstrasse, Schlieren,

ZH 8952, Switzerland

Full list of author information is available at the end of the article
}

dioxide $\left(\mathrm{CO}_{2}\right)$ narcosis, $\mathrm{O}_{2}$ must be provided in a controlled fashion with a target saturation of only $88-92 \%$ [3]. This recommendation was studied in a prehospital care setting of 405 patients with COPD exacerbations: When $\mathrm{O}_{2}$ was delivered via nasal prongs with a target percentage of oxygen saturation of arterial blood of 88$92 \%$, measured by pulse oximetry $\left(\mathrm{SpO}_{2}\right)$, a significantly lower in-hospital mortality ( $4 \%$ versus $9 \%, p=0.02$ ) was observed when compared with standard $\mathrm{O}_{2}$ delivery using a non-rebreathing mask [4]. In addition, there were fewer hypercapnic and acidotic episodes in the group with $\mathrm{O}_{2}$ delivered via a nasal cannula. Accordingly, the British Thoracic Society recommends three 
options for oxygen delivery to COPD patients at risk for hypercapnic respiratory failure: (i) Venturi mask $28 \%$ at $4 \mathrm{~L} / \mathrm{min}$. or Venturi mask $24 \%$ at $2-4 \mathrm{~L} / \mathrm{min}$. with a target $\mathrm{SpO}_{2}$ of $88-92 \%$. (ii) If the $\mathrm{SpO}_{2}$ falls below $88 \%, \mathrm{O}_{2}$ delivery should be changed to a nasal cannula with an $\mathrm{O}_{2}$ flow 2-6 L/min. or a simple face mask with an $\mathrm{O}_{2}$ flow of $5 \mathrm{~L} / \mathrm{min}$. (iii) Increases in partial pressure of carbon dioxide in arterial blood $\left(\mathrm{P}_{\mathrm{a}} \mathrm{CO}_{2}\right)$ or progressive acidotic $\mathrm{pH}$ require noninvasive ventilation or intubation and mechanical ventilation [5]. Non-rebreathing masks may be used in severely hypoxic patients. It is essential to set the $\mathrm{O}_{2}$ flow of non-rebreathing masks to 10-15 L/ min. in order to avoid $\mathrm{CO}_{2}$ rebreathing. Because of the risk of hypercapnic respiratory failure, blood gases must be analyzed every 30-60 minutes. We report the case of a patient with $\mathrm{COPD}$ who developed $\mathrm{CO}_{2}$ narcosis because of inadequate use of the non-rebreathing mask.

\section{Case presentation}

A 72-year-old, cachectic (height $170 \mathrm{~cm}$, weight $50 \mathrm{~kg}$, BMI $17.3 \mathrm{~kg} / \mathrm{m}^{2}$ ) Caucasian man with COPD and a history of smoking had increasing shortness of breath. Pulmonary function testing performed 9 years prior showed a decreased forced expiratory volume in 1 second $\left(\mathrm{FEV}_{1}\right)$ [38\% of predicted, Global Initiative for Chronic Obstructive Lung Disease (GOLD) stage 3], which did not increase after albuterol inhalation. The high total lung capacity and residual volume were consistent with emphysema. On arrival of the emergency medical team at his home, our patient was dyspneic but alert. His vital signs were: blood pressure 150/100 $\mathrm{mmHg}$, heart rate $103 \mathrm{bpm}$, and $\mathrm{SpO}_{2}$ 81\%. High-flow $\mathrm{O}_{2}$ was supplied at $10 \mathrm{~L} / \mathrm{min}$. using a non-rebreathing mask with an $\mathrm{O}_{2}$ reservoir bag (Fig. 1). The $\mathrm{SpO}_{2}$ increased to $99 \%$ within 20 minutes, and our patient was transported to the emergency department. As it was unknown whether our patient had a hypoxic respiratory drive, $\mathrm{O}_{2}$ flow was erroneously limited to $4 \mathrm{~L} / \mathrm{min}$. He got increasingly irritated, had no headache, but was no longer oriented to time, place, and person, and became unconscious, gasping for air 2 hours later. His blood pressure was $110 / 80 \mathrm{mmHg}$, and the heart rate was $80 \mathrm{bpm}$. Breath sounds were distant, and his tongue was cyanotic. An arterial blood gas analysis taken shortly after starting bagvalve-mask ventilation showed marked hypercapnia with respiratory acidosis (Table $1 \mathrm{~A}$ ). Noninvasive ventilation was not a possible option [6]. Our patient was intubated, mechanically ventilated, and received albuterol and ipratropium bromide by inhalation. Methylprednisolone, amoxicillin clavulante plus clarithromycin (for an infiltrate in the right paracardiac region), and low-dose theophylline were administered intravenously. Four hours later, our patient was extubated (Table 1B), and was later transferred to a medical ward. The high $\mathrm{P}_{\mathrm{a}} \mathrm{CO}_{2}$ was explained by low

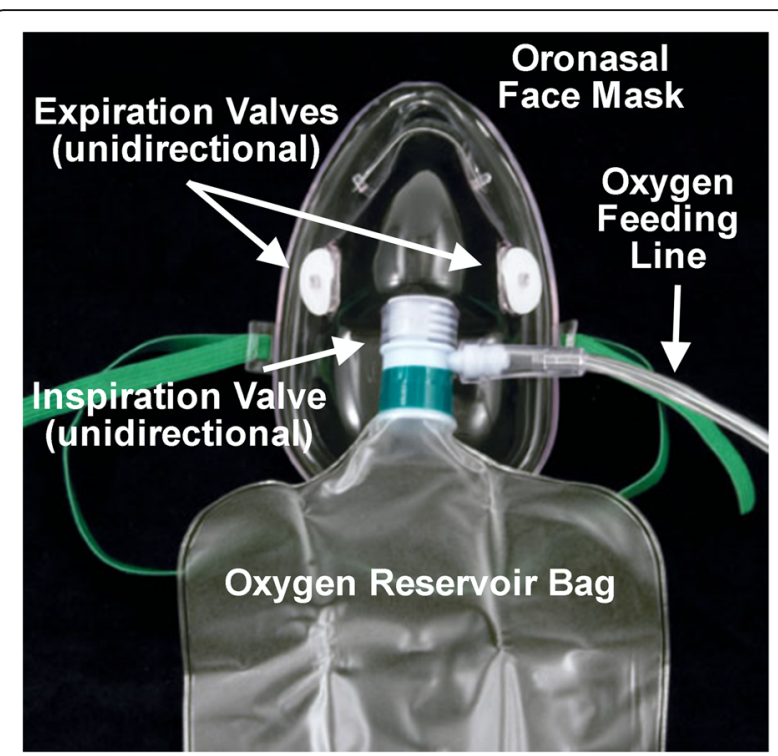

Fig. 1 Photograph of a non-rebreathing mask with an oxygen reservoir bag attached. The mask has one unidirectional inspiration valve and two unidirectional expiration valves. The carbon dioxide exhaled by the patient is constantly diluted by a high flow of oxygen delivered to the mask (10-15 L/min.)

tidal volumes and a probably hypoxic ventilatory drive (Table 1C). Because of our patient's worsening dyspnea, he mistakenly received $\mathrm{O}_{2}$ at $2 \mathrm{~L} / \mathrm{min}$. by the same nonrebreathing mask (Fig. 1). After a few hours, intensive care unit (ICU) admission was required due to hypotension $(75 / 50 \mathrm{mmHg})$ and bradypnea (Table $1 \mathrm{D})$. He was reintubated and mechanically ventilated for 24 hours. Norepinephrine was given to stabilize the blood pressure. An electrocardiogram (ECG) showed a sinus rhythm with right bundle branch block and right ventricular hypertrophy, and the echocardiography documented a chronic cor pulmonale with pulmonary arterial hypertension. Respiratory acidosis improved, and the patient was temporarily extubated (Table 1E). However, aspiration of a pea (removed by bronchoscopy, Fig. 2) with atelectasis of the right lung again necessitated mechanical ventilation and a tracheostomy. One month after admission, the exhausted patient died of $\mathrm{CO}_{2}$ narcosis (Table $1 \mathrm{~F}$ ). An autopsy was not performed.

\section{Discussion}

The first two episodes of $\mathrm{CO}_{2}$ narcosis (Table 1A, D) were due to near asphyxia and $\mathrm{CO}_{2}$ rebreathing because of incorrect use of the non-rebreathing mask by providing insufficient (2-4 L/min.) $\mathrm{O}_{2}$ supply. The third episode was due to probable hypoventilation and severe exhaustion (Table 1F).

Assuming a reduced tidal volume [7] of $200 \mathrm{~mL}$ (normal $7 \mathrm{~mL} / \mathrm{kg}$ body weight $=350 \mathrm{~mL}$ ) and a respiratory rate of $30 /$ min., our patient's estimated minute ventilation was 6 
Table 1 Arterial blood gas analyses at different time points during the hospital stay

\begin{tabular}{|c|c|c|c|c|c|c|}
\hline Time point (see text) & A, day 1 & B, day 1 & C, day 3 & D, day 4 & $\mathrm{E}$, day 5 & F, day 30 \\
\hline $\begin{array}{l}\mathrm{O}_{2} \text { flow rate; mode of } \\
\text { administration }\end{array}$ & $\begin{array}{l}4 \mathrm{~L} / \text { min.; non- } \\
\text { rebreathing mask }\end{array}$ & $\begin{array}{l}2 \mathrm{~L} / \mathrm{min} \text {.; nasal } \\
\text { cannula }\end{array}$ & $\begin{array}{l}2 \mathrm{~L} / \mathrm{min} \text {.; nasal } \\
\text { cannula }\end{array}$ & $\begin{array}{l}2 \mathrm{~L} / \text { min.; non- } \\
\text { rebreathing mask }\end{array}$ & $\begin{array}{l}2 \mathrm{~L} / \mathrm{min} \text {.; nasal } \\
\text { cannula }\end{array}$ & $\begin{array}{l}2 \mathrm{~L} / \mathrm{min} \text {.; tracheal } \\
\text { cannula }\end{array}$ \\
\hline $\mathrm{pH}(7.3-7.4)$ & 7.1 & 7.3 & 7.4 & 7.2 & 7.4 & 7.1 \\
\hline $\mathrm{P}_{\mathrm{a}} \mathrm{O}_{2}\left(\mathrm{kPa}^{\mathrm{a}}[11.1-14.4]\right)$ & 10.9 & 10.4 & 6.8 & 6.0 & 8.1 & 10.9 \\
\hline $\mathrm{P}_{\mathrm{a}} \mathrm{CO}_{2}\left(\mathrm{kPa}^{\mathrm{a}}[4.7-6.4]\right)$ & 20.0 & 9.3 & 7.8 & 15.8 & 8.3 & 20.7 \\
\hline $\begin{array}{l}\text { Bicarbonate } \\
\text { (mmol/L [24-31]) }\end{array}$ & 41.0 & 37.5 & 35.4 & 42.7 & 36.7 & 49.8 \\
\hline Base excess $(-1.5$ to +3.0$)$ & 3.0 & 8.2 & 9.1 & 9.4 & 10.5 & 17.7 \\
\hline $\mathrm{S}_{\mathrm{a}} \mathrm{O}_{2}(\%$ [95.0-99.9]) & 89.4 & 92.5 & 84.8 & 70.3 & 88.6 & 94 \\
\hline Respiratory rate & ND & 30 & 24 & Apneic & 30 & ND \\
\hline
\end{tabular}

$(\mathrm{L} / \mathrm{min} .[12-16])$

$N D$ not determined, $\mathrm{O}_{2}$ oxygen, $\mathrm{P}_{a} \mathrm{O}_{2}$ partial pressure of oxygen in arterial blood, $\mathrm{P}_{a} \mathrm{CO}_{2}$ partial pressure of carbon dioxide in arterial blood, $p \mathrm{H}$ power of hydrogen; negative logarithm of the hydrogen ion concentration, $\mathrm{S}_{a} \mathrm{O}_{2}$ percentage of oxygen saturation of arterial blood

${ }^{\mathrm{a}}$ To convert $\mathrm{kPa}$ to $\mathrm{mmHg}$, multiply by 7.5

$\mathrm{L} /$ minute (respiratory minute volume $[\mathrm{mL}]=$ tidal volume $[\mathrm{mL}] \times$ respiratory rate $[1 / \mathrm{min}$.]. The respiratory minute volume $[\mathrm{mL}]$ is also the sum of the alveolar ventilation $[\mathrm{mL}]+$ the dead space ventilation $[\mathrm{mL}])$. In highconcentration reservoir masks only an $\mathrm{O}_{2}$ flow that exceeds the minute ventilation guarantees a sufficient air supply. Consequently, the reservoir bag of the nonrebreathing mask must not be allowed to deflate by more than one third during inspiration. Our patient's respiratory dead space was $100 \mathrm{~mL}$ ( $2 \mathrm{~mL} / \mathrm{kg}$ body weight), and the dead space of the mask was $50 \mathrm{~mL}$. The increased dead space (150 versus $100 \mathrm{~mL}$ ) was relevant for gas exchange; the alveolar ventilation decreased from $3 \mathrm{~L} / \mathrm{min}$. to $1.5 \mathrm{~L} /$ min., which substantially compromised gas exchange. Furthermore, due to insufficient washout by the low $\mathrm{O}_{2}$ flow

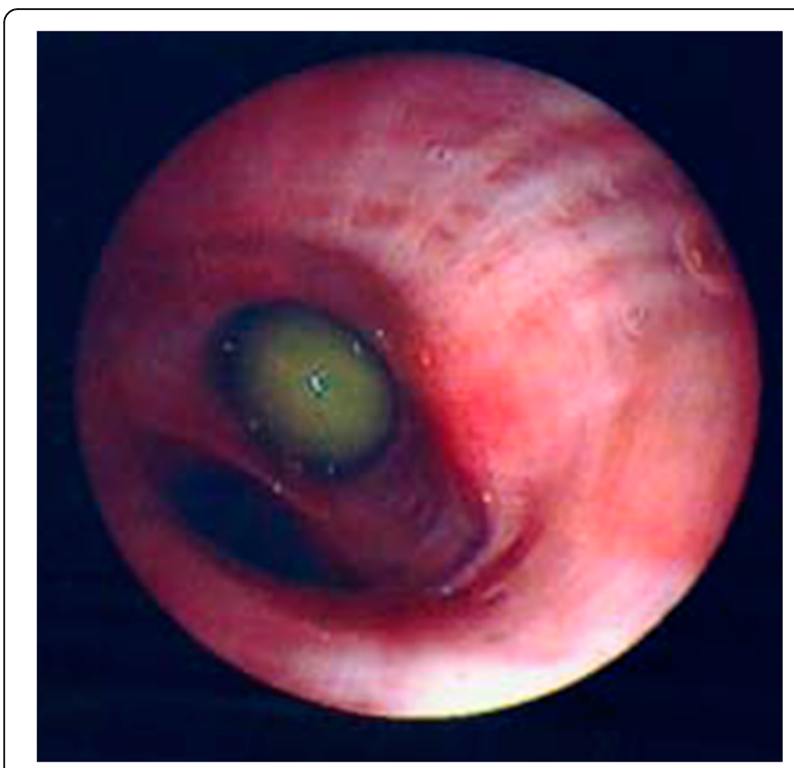

Fig. 2 Photograph made during bronchoscopy on day 10. A pea is visible in the bronchus to the right laterobasal pulmonary segment to the face mask [8], our patient rebreathed a toxic amount of $\mathrm{CO}_{2}$. Our patient was unable to increase his low tidal volume, and an increase in the respiratory rate was insufficient, given the considerable ventilatory dead space.

Jensen et al. examined the effect of different oxygen flow rates on ventilation parameters and gas exchange in ten healthy volunteers wearing a simple oronasal face mask (Hudson ) without a reservoir bag. Lowering the oxygen supply from 5 to $0 \mathrm{~L} / \mathrm{min}$. led to an increase in minute ventilation from 4.8 to $7.5 \mathrm{~L} / \mathrm{min}$. due to an increase in tidal volume from 380 to $540 \mathrm{~mL}$ with almost no change in respiratory rate. The $\mathrm{P}_{\mathrm{a}} \mathrm{O}_{2}$ decreased from 38 to $13 \mathrm{kPa}$, the $\mathrm{S}_{\mathrm{a}} \mathrm{O}_{2}$ from $100 \%$ to $96 \%$, while the $\mathrm{P}_{\mathrm{a}} \mathrm{CO}_{2}$ remained unchanged. The authors inferred from their results that $\mathrm{CO}_{2}$ retention will occur in patients with COPD wearing a simple oronasal face mask with an $\mathrm{O}_{2}$ supply set to $<5 \mathrm{~L} /$ minute, because these patients cannot increase their tidal volumes [8].

In severely hypoxemic patients with $\mathrm{COPD}, \mathrm{O}_{2}$ may be delivered using a non-rebreathing mask with a target $\mathrm{O}_{2}$ flow rate of $10-15 \mathrm{~L} / \mathrm{min}$. Arterial blood gases must be analyzed regularly. Approximately $13 \%$ of patients with COPD admitted with an exacerbation of their disease will develop $\mathrm{CO}_{2}$ retention during controlled $\mathrm{O}_{2}$ therapy [2]. In this case, it is important not to stop the $\mathrm{O}_{2}$ flow completely because of the risk of rebound hypoxemia [9]. For a target $\mathrm{S}_{\mathrm{a}} \mathrm{O}_{2}$ of $88-92 \%$, an $\mathrm{O}_{2}$ supply via nasal cannula with an $\mathrm{O}_{2}$ flow rate of $1-2 \mathrm{~L} /$ minute is usually sufficient [5]. If not, either noninvasive or mechanical ventilation must be considered [6]. Paramedics may safely use low-inspired $\mathrm{O}_{2}$ flow $(\leq 4 \mathrm{~L} / \mathrm{min}$.) by nasal cannula initially in patients with COPD exacerbations [10].

\section{Conclusions}

Non-rebreathing masks with $\mathrm{O}_{2}$ reservoir bags must be fed with an $\mathrm{O}_{2}$ flow exceeding the patient's minute ventilation $(>6-10 \mathrm{~L} / \mathrm{min}$.). If not, the amount of oxygen 
delivered will be too small to effectively increase the arterial $\mathrm{O}_{2}$ saturation. Moreover, the risk of $\mathrm{CO}_{2}$ rebreathing dramatically increases if the flow of oxygen to a non-rebreathing mask is lower than the minute ventilation, especially in patients with COPD and low tidal volumes. As a consequence, $\mathrm{CO}_{2}$ narcosis may develop. Non-rebreathing masks (with $\mathrm{O}_{2}$ reservoir bags) must be used cautiously by experienced medical staff and correctly with an appropriately high $\mathrm{O}_{2}$ flow of 10-15 L/ min. $[5,11]$. Nevertheless, arterial blood gases must be analyzed regularly for early detection of a rise in $\mathrm{P}_{\mathrm{a}} \mathrm{CO}_{2}$ in patients with COPD and a hypoxic ventilatory drive. These patients are more safely managed using a nasal cannula with an $\mathrm{O}_{2}$ flow of $1-2 \mathrm{~L} / \mathrm{min}$. or a simple face mask with an $\mathrm{O}_{2}$ flow of $5 \mathrm{~L} / \mathrm{min}$. [5].

\section{Abbreviations \\ BMI: Body mass index; $\mathrm{CO}_{2}$ : Carbon dioxide; $\mathrm{COPD}$ : Chronic obstructive pulmonary disease; $\mathrm{FEV}_{1}$ : Forced expiratory volume in 1 second; GOLD: Global Initiative for Chronic Obstructive Lung Disease; $\mathrm{O}_{2}$ : Oxygen; $\mathrm{P}_{2} \mathrm{CO}_{2}$ : Partial pressure of carbon dioxide in arterial blood; $\mathrm{P}_{2} \mathrm{O}_{2}$ : Partial pressure of oxygen in arterial blood; $\mathrm{S}_{a} \mathrm{O}_{2}$ : Percentage of oxygen saturation of arterial blood; $\mathrm{S}_{\mathrm{p}} \mathrm{O}_{2}$ : Percentage of oxygen saturation of arterial blood, measured by pulse oximetry}

\section{Acknowledgements}

Not applicable.

\section{Funding}

Article processing charges were defrayed by the Forschungsfonds of the Spital Limmattal.

\section{Availability of data and materials \\ Not applicable.}

\section{Authors' contributions}

TH drafted the manuscript and created the figures. EA performed the bronchoscopy and had an important role in writing and reviewing the manuscript. T Hegi was in charge of the patient during his stay in the intensive care unit. He had a role in writing and reviewing the manuscript. AR critically reviewed the manuscript. MS conceived of the case report, and assisted in drafting the manuscript. All authors read and approved the final manuscript.

\section{Authors' information}

MS is President of the Verein Komplikationenliste. Under the auspices of the Swiss Society of General Internal Medicine the Verein Komplikationenliste uses a program for the anonymous, systematic and prospective registration of iatrogenic complications of medical interventions in hospitalized patients in Switzerland. The patient reported was part of this registry.

\section{Ethics approval and consent to participate}

Involvement of the ethics committee of the Canton of Zurich was not considered necessary, since the writing of a case report was not based on a study protocol, and is not classified as research by the Swiss Federal Act on Research on Human Beings.

\section{Consent for publication}

Written informed consent was obtained from the patient's next-of-kin for publication of this case report and all accompanying images. A copy of the written consent is available for review by the editor of this journal.

\section{Competing interests}

The authors declare that they have no competing interests.

\section{Publisher's Note}

Springer Nature remains neutral with regard to jurisdictional claims in published maps and institutional affiliations.

\section{Author details}

${ }^{1}$ University of Zurich, Medical Faculty, Zurich, Switzerland. ${ }^{2}$ Department of Medicine, Limmattal Hospital, 100 Urdorferstrasse, Schlieren, ZH 8952, Switzerland. ${ }^{3}$ Institute of Anesthesiology and Intensive Care, Limmattal Hospital, 100 Urdorferstrasse, Schlieren, ZH 8952, Switzerland. ${ }^{4}$ University of Basel, Medical Faculty, Basel, Switzerland. ${ }^{5}$ Department of Anesthesiology and Intensive Care, Zollikerberg Hospital, 20 Trichtenhauser Strasse, Zollikerberg, ZH 8125, Switzerland. ${ }^{6}$ University of Bern, Medical Faculty, Bern, Switzerland. 7 Verein Komplikationenliste, Swiss Society of General Internal Medicine, 4 Lebernhöhe, Ebmatingen, ZH 8125, Switzerland.

Received: 10 April 2017 Accepted: 23 June 2017

Published online: 28 July 2017

\section{References}

1. Agusti AG, Vogelmeier C. Global Strategy for the Diagnosis, Management and Prevention of COPD, Global Initiative for Chronic Obstructive Lung Disease (GOLD). 2017. Available from: http://goldcopd.org. Accessed 27 Mar 2017.

2. Moloney ED, Kiely JL, McNicholas WT. Controlled oxygen therapy and carbon dioxide retention during exacerbations of chronic obstructive pulmonary disease. Lancet. 2001;357:526-8.

3. O'Driscoll R. Emergency oxygen use. BMJ. 2012:345:e6856.

4. Austin MA, Wills KE, Blizzard L, Walters EH, Wood-Baker R. Effect of high flow oxygen on mortality in chronic obstructive pulmonary disease patients in prehospital setting: randomised controlled trial. BMJ. 2010;341:c5462.

5. O'Driscoll BR, Howard LS, Davison AG, British Thoracic S. BTS guideline for emergency oxygen use in adult patients. Thorax. 2008;63 Suppl 6:vi1-68

6. Brochard L, Mancebo J, Wysocki M, Lofaso F, Conti G, Rauss A, Simonneau G, Benito S, Gasparetto A, Lemaire F, et al. Noninvasive ventilation for acute exacerbations of chronic obstructive pulmonary disease. N Engl J Med. 1995:333:817-22.

7. Loveridge $B$, West $P$, Kryger MH, Anthonisen NR. Alteration in breathing pattern with progression of chronic obstructive pulmonary disease. Am Rev Respir Dis. 1986;134:930-4.

8. Jensen AG, Johnson A, Sandstedt S. Rebreathing during oxygen treatment with face mask - the effect of oxygen flow-rates on ventilation. Acta Anaesthesiol Scand. 1991;35:289-92.

9. Kane B, Turkington PM, Howard LS, Davison AG, Gibson GJ, O'Driscoll BR. Rebound hypoxaemia after administration of oxygen in an acute exacerbation of chronic obstructive pulmonary disease. BMJ. 2011:342:d1557.

10. Durrington HJ, Flubacher M, Ramsay CF, Howard LS, Harrison BD. Initial oxygen management in patients with an exacerbation of chronic obstructive pulmonary disease. QJM. 2005;98:499-504.

11. Kallstrom TJ, American Association for Respiratory C. AARC Clinical Practice Guideline: oxygen therapy for adults in the acute care facility-2002 revision \& update. Respir Care. 2002:47:717-20.

Submit your next manuscript to BioMed Central and we will help you at every step:

- We accept pre-submission inquiries

- Our selector tool helps you to find the most relevant journal

- We provide round the clock customer support

- Convenient online submission

- Thorough peer review

- Inclusion in PubMed and all major indexing services

- Maximum visibility for your research

Submit your manuscript at www.biomedcentral.com/submit
) Biomed Central 